\title{
The Role and Practice of Clinical Nurse Specialist in Nigeria
}

\author{
Primary Author \\ Chidiebele Constance Obichi, RN, PhD \\ Indiana University School of Nursing, Northwest \\ 3400 Broadway \\ Gary, IN 46408 \\ Phone: 404-246-8637 \\ Email: consobichi2000@yahoo.com
}

\author{
Co-author \\ Anieche John Emenike, RN, MSc, FWACN \\ Department of Nursing Science, Faculty of Health Sciences and Technology, Nnamdi Azikiwe \\ University Nnewi Campus. P.M.B 5001 Nnewi, Anambra State, Nigeria \\ Phone: +2348066414521 \\ Email: je.anieche@unizik.edu.ng \\ Co-author \\ Osuala Eunice Ogonna, RN, MPH, PhD, FWACN \\ Department of Nursing Science, Faculty of Health Sciences \& Technology, Nnamdi Azikiwe \\ University, Nnewi Campus. P.M.B 5001 Nnewi, Anambra State, Nigeria. \\ Phone: +2348061146538 \\ Email: eo.osuala@unizik.edu.ng
}

\author{
Co-author \\ Oruche Ukamaka Marian PhD, RN, FAAN \\ Indiana University School of Nursing \\ 600 Barnhill Drive \\ Indianapolis, IN 46202 \\ Phone: $317-418-5355$ \\ Email: uoruche@iu.edu
}

This is the author's manuscript of the work published in final edited form as:

Obichi, C. C., Anieche, J. E., Osuala, E. O., \& Oruche, U. M. (2021). The Role and Practice of Clinical Nurse Specialist in Nigeria. In J. S. Fulton \& V. W. Holly (Eds.), Clinical Nurse Specialist Role and Practice: An International Perspective (pp. 225-232). Springer International Publishing. https://doi.org/10.1007/9783-319-97103-2 17 


\title{
Clinical Nurse Specialist Role and Practice in Nigeria
}

\begin{abstract}
Although the clinical nurse specialist was recognized as an expert practitioner in the United States since 1974, there is an absence of a framework for the clinical nurse specialist role in Nigeria. There are three pathways through which the federal government, state government, and the private sector provide specialist education and training for nurses in Nigeria. Nurses who have received graduate education should practice to the full extent of their education and training. Also, nurses who have their practice expanded in the treatment of communicable diseases and reproductive, maternal, newborn and child care should be rewarded appropriately. This chapter explores the challenges to developing the clinical specialist nurse role and the extent to which the clinical nurse specialist role is evolving in Nigeria through specialist education and training for nurses. Regardless of the pathway, setting, or specialty, Nigerian nurses may have achieved the clinical nurse specialist core competencies without a formal master's education. Hence, Nigeria is long overdue for the development, recognition, and legal inclusion of the clinical nurse specialist role and practice in the career structure of nurses at all levels of the Nigerian health system.
\end{abstract}

Keywords: Nigeria, specialist, nurses, clinical, advanced practice, education, midwives 


\section{The Clinical Nurse Specialist}

Although the Clinical Nurse Specialist (CNS) was recognized as an expert practitioner in the United States (US) since $1974,{ }^{1-2}$ there is an absence of a framework for the CNS role and practice in Nigeria. The CNS role is one of the four advanced practice registered nurse roles in the US which has evolved as a result of the societal need to address the increasing complexity of patients that require specialized acute nursing care and to improve access to quality and affordable care at primary care clinics..$^{3-4}$

According to the US National Association of Clinical Nurse Specialists, CNSs are registered nurses with graduate or post-graduate certification from an accredited program prepared to practice for a specialty population and are clinical experts in the diagnosis and treatment of illness, delivery of evidence-based nursing interventions; advancement of nursing practice and improvement of outcomes, and may act as independent licensed provider which includes prescribing medications. ${ }^{1}$ A clinical nurse specialist's specialty may be defined by: population (pediatrics, geriatrics, women's health); setting (critical care, emergency room); disease or medical subspecialty (diabetes, oncology); type of care (psychiatric, rehabilitation); or type of problem (such as: pain, wounds, stress). ${ }^{1}$

This chapter explores the challenges to developing the clinical specialist nurse role and practice and the extent to which the clinical nurse specialist role is evolving in Nigeria through specialized education and training for nurses and nurse midwives.

\section{Brief History of Nursing Education and Training in Nigeria}

Nursing education in Nigeria is either university-based or hospital-based (apprenticeship) and is provided by the federal and state governments and the private sector (missionary and individual organizations). The majority of nurses in Nigeria obtain their education through 
hospital-based nursing programs which began in 1949. These programs offer generic nursing or basic nursing education and training in the hospital setting. Nigerian hospitals do not award academic qualifications; hence, graduates of hospital-based programs earn a higher national diploma certificate and are registered and licensed upon graduation. The majority of these RNs work in acute care hospitals and community health centers. ${ }^{5-7}$

The preparation of nurses with bachelor of nursing science (BNSc) degree began in 1965 with approval by the National Universities Commission (NUC) and the Nursing \& Midwifery Council of Nigeria $(\mathrm{N} \& \mathrm{MCN})$. However, graduates of these undergraduate programs were very few that in 1999 the federal government approved private baccalaureate nursing programs to increase the number of BNSc-prepared nurses (Ojo \& Onasoga, 2009). Graduates of all nursing programs are professionally registered and licensed by the N\&MCN to work in hospital and community settings such as schools, health centers, and manufacturing industries. ${ }^{5-7}$ These nurses are expected to:

- utilize the nursing process in providing care

- $\quad$ assist patients with coping with the biological and environmental changes experienced during hospitalization

- ensure safety and implement nursing interventions in collaboration with the health care team

- conduct and participate in research towards improvement of patient care and growth of the nursing profession

- participate in effective budgeting and auditing of the unit

- participate in evidence-based nursing practice

- participate in architectural design of Clinical Services Department to effect efficiency and quality patient care. ${ }^{6}$ 
Following reports about the critical health workforce shortage in developing countries, the World Health Organization $(\mathrm{WHO})^{8}$ recommended "task shifting," a public health approach to: address the HIV epidemic, increase access to health services, and strengthen the overall health system of countries deficient in human resources for health. The goal was to enable existing health care workers such as nurse midwives to provide care according to an extended scope of practice at all levels of the national health system and to allow creation of new roles within the health workforce. In 2014, the Nigerian National Council of Health ${ }^{9}$ approved the Task-Shifting Policy and the implementation of task shifting commenced especially in the rural and underserved areas. ${ }^{10}$ Task-shifting type II is the "extension of the scope of practice of nurses and midwives in order to enable them assume some tasks previously undertaken by medical doctors and non-physician clinicians (professional health workers who are not trained as physicians but capable of many of the diagnostic and clinical functions of a medical doctors and have more clinical skills than generic nurses and are present both in high-income and lowincome countries). ${ }^{10}$ The task shifting model from physicians to nurses has expanded the role of nurses as the primary medical care provider for mothers with HIV and AIDS. This model has been used successfully in treating HIV patients in Nigeria, ${ }^{11-12}$ South Africa, ${ }^{13}$ and Rwanda, ${ }^{14}$ and to reduce maternal and fetal mortality and morbidity in Ethiopia. ${ }^{15}$

\section{Pathways to CNS Role and Practice in Nigeria}

The three existing pathways to specialized nursing education and training provide the platform on which the CNS role and practice would evolve in Nigeria. The pathways include 1) hospital-based pathway, 2) University-based pathway, and 3) the task-shifting pathway. Each pathway is presented below.

\section{Hospital-based Pathway}

The hospital-based generic or basic nursing diploma is a three-year program and is the first step prior to obtaining specialized nursing education and training. After one or two years of clinical experience, a post-basic specialized training (PBST) that lasts between $12-24$ months 
follows with the RN focusing on a specific area of nursing (majority choose midwifery). To obtain further specialized education, the RN may acquire multiple certifications in specialties of their choice. ${ }^{6-7}$ Upon completion of the PBST, graduates are certified, registered, and licensed by the N\&MCN to practice in their areas of specialty which include intensive care, midwifery, burns and plastic, pediatric, accident and emergency care, ophthalmic, orthopedics, nephrology, mental and psychiatric health, perioperative, oncology, community health nursing, and anesthesiology. Research indicates that PBST nurses have impacted the Nigerian health system in the following ways: increased patient satisfaction, decrease in medical complications; decrease in frequency of emergency cases and deaths, improved pain management, and decrease in the length of hospital stay and costs to patients. ${ }^{16}$

Although the majority of Nigeria nurses are trained in hospital-based programs, this form of education and training is devoid of liberal education, opportunities for creativity, accountability, independent clinical decision making, understanding and appropriate utilization of: the nursing process, evidence-based practice, and advanced nursing practice skills. ${ }^{7,16}$ Thus, the RN with PBST may enroll in a university-based 4-year program (also known as direct entry) to obtain a BNSc degree. Overall, a nurse that follows the hospital-based pathway spends a minimum of eight years to obtain an RN license ( 3 years), a certification in one nursing specialty (1 year) and a BNSc in nursing (4 years). Hence, the saying that "Nigerian nurses are over trained at the diplomate level due to unnecessary overlap in education between the diploma and baccalaureate programs." Consequently, many PBST nurses are slow in embracing university education, ${ }^{7}$ so their specialized education and training are not obtained at the graduate level. However, with their minimum 8-year long training and many years of clinical experience these nurses may provide nursing care that they were not formally trained for especially in rural and underserved areas of the country.

\section{University-based Pathway}


To receive the university-based specialized education and training at the graduate level (master's and doctor of philosophy $[\mathrm{PhD}]$ ), the potential candidate must as a first step complete a five-year BNSc program. Upon completion of the BNSc, graduates are registered by the N\&MCN as "generic" nurses (RN), registered midwives (RM), and registered public health nurses (RPHN). The next step would be to obtain a master's degree in one of the specialties. For example, maternal \& child health, medical-surgical, mental health \& psychiatric, administration and management, nursing education, and community health nursing. Upon completion of the master's or PhD program, graduates are equipped for careers in clinical settings, administration and management, education and research at all levels of health care and educational institutions, as well as corporate organizations and other relevant agencies. ${ }^{6}$ Although master's prepared nurses should practice to the full extent of their education and training, the majority of them are employed in academia because advanced clinical roles are non-existing and there is no national framework and guidelines to recognize and reward growth in clinical nursing practice in Nigeria. ${ }^{17}$

\section{Task Shifting Pathway}

Task shifting involves redistributing specific tasks, where appropriate, from highly qualified health workers to health workers with shorter training and fewer qualifications in order to make more efficient use of the available human resources for health. ${ }^{9}$ Nigerian nurses and nurse midwives have had their practice expanded in the treatment of HIV infection, and reproductive, maternal, newborn and child care. ${ }^{10}$ They:

- provide early infant male circumcision

- repair cervical laceration and complex vaginal laceration

- assess client's readiness to commence Antiretroviral therapy (ART)

- manage severe pregnancy and labor complications (anemia, preeclampsia, eclampsia, malaria fetal malpresentations, prolonged and/or obstructed labor, hypertension, bleeding, and infection) 
- issue prescription for antiretrovirals (ARV) regimen and refer to pharmacy

- diagnose severe HIV diseases and confirm HIV infection.

Further, research indicates that in Nigeria task-shifting to nurses and nurse midwives decreased patients' wait times by $62 \%$; decreased physician workload by $41 \% ;{ }^{12,18}$ improved job satisfactions for nurses and retained more patients in HIV settings. ${ }^{11}$

Although task shifting is in the early stages of implementation in Nigeria, the medical and nursing regulatory bodies are yet to standardize recruitment, training, and evaluation criteria to assess its positive impact on the health system. Equally important are the development of: 1) standard context-relevant curriculum ${ }^{19}$ for training and continual education; 2) regulatory framework to define CNS role and scope of practice for existing health workforce; 3) establish competencies for CNS; and provide guidelines for 1) immediate opportunities for referral to medical doctors; 2) regular supportive supervision and clinical mentoring from physicians and non-physician clinicians; and 3) systematic collection of strategic information concerning the implementation of the task shifting model. ${ }^{9}$

\section{Moving Forward: Challenges and Opportunities}

According to Ayandiran et al., there is a critical need to utilize nurses with higher education in Nigeria to promote critical thinking and increase use of evidence-based nursing practice. ${ }^{5}$ The hallmarks of CNS practice are: integrating evidence-based practice into health care; designing programs of care and innovative nursing interventions; and providing leadership and education to nurses. ${ }^{3}$ Higher education is essential for moving forward with these core CNS responsibilities. According to Sun and Larson ${ }^{20}$ translation of evidence-based practice from research to frontline nursing is possible when there are well-trained scholars who usually receive their training from graduate programs. In 2008, the Fellows of West African College of Nursing $(\mathrm{FWACN})^{21}$ proposed the development of the Advanced Nurse Practitioner role for the West African sub-region, however, not much has been achieved since the proposal was presented. 
The challenges to developing advanced practice roles include professional rivalry between nurses and doctors and fear of losing earnings. In a study ${ }^{22}$ that explored the perception of 24 nurses about the factors that hinder the development of the advanced nurse practitioner role in five southeastern states of Nigeria, a chief nursing officer (participant) stated, "The doctors think that nurses will take over their jobs or replace them." Another challenge was from medical doctors who were concerned about unethical conduct, poor quality and management, and abuse of roles by nurses. Another hindrance was from medical organizations on the grounds that advanced nursing practice would negatively impact their role in Africa and that nurses had insufficient training for the expanded roles. Other challenges include limited resources and cost of training, mentoring, support and supervision of expanded roles. ${ }^{21-26}$

Further, research with a clinical focus is among the most lacking in nursing and midwifery research in Africa. ${ }^{20}$ In Nigeria, the majority of nurses who obtain graduate nursing degrees prefer to join academia, hence, nursing faculty conduct more research than nurses in clinical settings. There is, therefore, a dearth of research in the hospital setting related to the lack of master's and doctorally prepared nurses in the clinical setting. It is vital to note that a handful of nurses who obtain their masters while providing direct patient care in the hospitals continue with direct patient care despite their advanced nursing degree and are neither recognized for professional growth nor rewarded by employers. Research indicates that barriers that hinder nurses from conducting research in health facilities include lack of understanding of research priorities; inadequate staff; lack of experienced nurse researchers, organizational support and funding; absence of nursing research mentors, and lack of leadership in the dissemination of research findings. ${ }^{5}$

\section{Conclusion}

Regardless of the pathway, setting, or specialty, Nigeria is long overdue for the development, recognition, and legal inclusion of the CNS role and practice in the career structure of nurses at all levels of the health system. Nurses and nurse midwives in Nigeria may 
have achieved the CNS core competencies without formal master's education. Hence, the N\&MCN should collaborate with professional nursing associations (National Association for Nigerian Nurses and Midwives (NANNM); National Association of Nigerian Nurses in North America (NANNNA); and other nursing specialty associations) and all stakeholders to push policy that would: recognize advanced degree nurses in the clinical settings with appropriate salary scale; establish standards for CNS role and practice; and develop the CNS curriculum with master's level courses that include opportunities for content-specific clinical experiences and preceptorship. 


\section{References}

1. National Association of Clinical Nurse Specialists. Statement on clinical nurse specialist practice and education. NACNS; 2004.

2. Hamric, Ann B., Judith A. Spross, and Charlene M. Hanson. Advanced Practice Nursing: An Integrative Approach. St. Louis: Saunders Elsevier, 2009.

3. Gordon JM, Lorilla JD, Lehman CA. The role of the clinical nurse specialist in the future of health care in the United States. Perioperative Nursing Clinics. 2012 Sep 1;7(3):34353

4. Dunn L. A literature review of advanced clinical nursing practice in the United States of America. Journal of Advanced Nursing [serial on the Internet]. (1997, Apr), [cited May 14, 2018]; 25(4): 814-819.

5. Ayandiran EO, Irinoye OO, Faronbi JO, Mtshali NG. Education reforms in Nigeria: how responsive is the nursing profession? International Journal of Nursing Education Scholarship. 2013;10(1):11-19.

6. University of Nigeria Teaching Hospital. Specialized education and training http://www.unthenugu.com.ng/education_training.html. 2018

7. Agbedia C. Re-envisioning nursing education and practice in Nigeria for the $21 \mathrm{st}$ century. Open Journal of Nursing. 2012 Sep 28;2(03):226-230.

8. World Health Organization (WHO). Task shifting: rational redistribution of tasks among health workforce teams: global recommendations and guidelines. Geneva: WHO; 2008. TTR-Task Shifting. pdf $</$ url $>$ (accessed 11 May 2014). 2008 
9. Federal Ministry of Health. FG, Partners to Scale Up Family Planning Access. Retrieved from http://www.health.gov.ng/index.php/component/content/article/78-featured/465-fgpartners-to-scale-up-family-planning-access, 2018.

10. Federal Ministry of Health. Task-Shifting and Task-Sharing Policy for Essential Health Care Services in Nigeria. 2014. Retrieved from http://www.health.gov.ng/doc/TSTS.pdf

11. Iwu EN, Holzemer WL. Task shifting of HIV management from doctors to nurses in Africa: clinical outcomes and evidence on nurse self-efficacy and job satisfaction. AIDS Care. 2014 Jan;26(1):42-52.

12. Iwu E, Ezebuihe I, Caroline O, Umaru E, Gomwalk A, Moen M, Riel R, Johnson J. Task shifting-a strategic response to human resource for health crisis: qualitative evaluation of hospital-based HIV clinics in North central Nigeria. International AIDS Conference, Vienna 2010.

13. Sanne I, Orrell C, Fox M, Conradie F, Ive P, Orrell C, et al. Nurse versus doctor management of HIV-infected patients receiving antiretroviral therapy (CIPRA-SA): a randomised non-inferiority trial. Lancet [serial on the Internet]. (2010, July 3), [cited May 18, 2018]; 376 North American Edition (9734): 33-40.

14. Shumbusho F, van Griensven J, Lowrance D, Turate I, Weaver M, Binagwaho A, et al. Task shifting for scale-up of HIV care: evaluation of nurse-centered antiretroviral treatment at rural health centers in Rwanda. Plos Medicine [serial on the Internet]. (2009, Oct), [cited May 18, 2018]; 6(10): e1000163.

15. Gessessew A, Barnabas G, Prata N, Weidert K. Task shifting and sharing in Tigray, Ethiopia, to achieve comprehensive emergency obstetric care. International Journal of Gynecology \& Obstetrics [serial on the Internet]. (2011, Apr), [cited May 18, 2018]; 113(1): 28-31.

16. Ojo. AA \& Onasoga O A. In: Current Trends \& issues in Nursing in Nigeria pri RoyalBird ventures Ltd., Mushin, Lagos. 2009 
17. Chiegboka I. Establishing a National Framework and Guidelines for Professional Development and Recognition Programme in Nigeria as a Necessity for Nursing Clinical Excellence. West African Journal of Nursing [serial on the Internet]. (2015, May), [cited May 18, 2018]; 26(1): 82-87.

18. Udegboka N, Moses John H. Reduction of client waiting time through task shifting in Northern Nigeria. International AIDS Conference on HIV Pathogenesis, Treatment and Prevention, Cape Town 2009.

19. Iwasiw, Carol, Dolly Goldenberg, and Mary-Anne Andrusyszyn. Curriculum Development in Nursing Education. Jones \& Bartlett Publishers, 2008.

20. Sun C, Larson E. Clinical nursing and midwifery research in African countries: A scoping review. International Journal of Nursing Studies [serial on the Internet]. (2015, May), [cited May 18, 2018]; 52(5): 1011-1016.

21. G. Madubuko. Nurse Practitioner/Advanced Nursing Practice Development in West Africa: A Proposal. https://international.aanp.org/Content/docs/WestAfrica.pdf

22. C. G. Ugochukwu, A. I. Nnabuenyi and C. Ndubuka. Advanced Practice Nursing challenges in developing countries: perception of nurses in selected health care facilities in SouthEastNigeria.http://www.commonwealthnurses.org/conference2014/Documents/ ChikaUgochukwu.pdf

23. Oloo A. Upgrade skills in health care. The East African. Nov 9, 2003. http://www.nationaudio.com/News/DailyNation/09112003/Letters/Letters1.html

24. Mullan F, Frehywot S. Non-physician clinicians in 47 sub-Saharan African countries. Lancet [serial on the Internet]. (2007, Dec 22), [cited May 18, 2018]; 370(9605): 21582163

25. Dovlo D. Using mid-level cadres as substitutes for internationally mobile health professionals in Africa. A desk review. Human Resources for Health [serial on the Internet]. (2004, Jan), [cited May 18, 2018]; 27-12. 
26. The Nigerian Medical Association. Communique issued at the end of the meeting of the National Executive Council of the Nigerian Medical Association held from the 26th to 28th August, 2005 in Maiduguri, Borno State; 2005. http://www.nigeriannma.org 